Voix et Images

voixetimages

\title{
Le Canada imaginaire des Français
}

\section{Lucie Robert}

Volume 14, numéro 1 (39), automne 1988

France Théoret : narratrice de la subjectivité

URI : https://id.erudit.org/iderudit/200757ar

DOI : https://doi.org/10.7202/200757ar

Aller au sommaire du numéro

\section{Éditeur(s)}

Université du Québec à Montréal

ISSN

0318-9201 (imprimé)

1705-933X (numérique)

Découvrir la revue

Citer cet article

Robert, L. (1988). Le Canada imaginaire des Français. Voix et Images, 14(1),

123-124. https://doi.org/10.7202/200757ar d'utilisation que vous pouvez consulter en ligne.

https://apropos.erudit.org/fr/usagers/politique-dutilisation/ 


\section{Le Canada imaginaire des Français}

\section{par Lucie Robert, Université du Québec à Montréal}

Dans Mythe et reflet de la France ${ }^{1}$, vérsion remaniée d'une thèse de doctorat soutenue à l'Université de Bordeaux en 1975, Sylvain Simard tente de reconstituer le substrat du Canada imaginaire des Français, en étudiant un ensemble de textes qui, de 1850 à 1914, dans divers domaines se sont consacrés ou ont fait une part plus ou moins importante d la réalité canadienne (p. 12), c'est-à-dire près de sept cents ouvrages, livres, brochures, articles de la presse périodique. Les dates limitrophes définissent une période où des relations importantes se sont instaurées à plusieurs niveaux (p. 10) et où des Français ont redécouvert la colonie perdue et ses habitants. Situées dans le prolongement des travaux de Jean Ménard et d'Armand Yon ${ }^{2}$, pour ne citer que ces deux-là, les recherches de Sylvain Simard renouent avec la problématique des relations entre la France et le Québec qui, dans le champ des études littéraires, n'ont été que peu explorées.

Comme toutes les études qui manipulent un corpus important, celle-ci a ses qualités et ses limites. Un aussi vaste ensemble de textes permet d'atteindre rapidement l'objectif fixé par l'analyse des éléments redondants et des recoupements. L'analyse du discours, méthodologie de lecture utilisée ici, a toutefois le désavantage d'aplanir les différences, d'uniformiser et d'accorder des sens, des images et des textes qui devraient apparaître comme plus polémiques et certainement plus discordants. Cela dit, je ne saurais reprocher à l'auteur son efficacité, d'autant moins qu'il a eu la prudence de spécifier la notion d'image, qu'il utilise de préférence à celle d'opinion publique (quoique dans ce domaine les travaux de Marc Angenot aient permis des développements théoriques plus intéressants), de 
distinguer les images produites par les récits de voyages des images de fiction, et de prendre en considération la sociologie des textes et de leurs auteurs.

Serons-nous vraiment étonnés d'apprendre que le tiers de ceux qui ont publié une étude sur le Canada n'y ont jamais mis les pieds, que la moitié de ceux qui y sont venus n'y ont passé que quelques jours, comme appendice à un voyage dont la destination première était les États-Unis, et que le trajet type du voyageur remontait le Saint-Laurent jusqu'aux Grands Lacs et à Niagara, éliminant autant de régions et de territoires de leurs considérations. Serons-nous surpris d'apprendre que la littérature québécoise n'a que peu d'écho en France et que les ouvrages français, mis à part quelques romans d'aventures destinés à la jeunesse surtout, ne montrent que fort peu d'intérêt pour le Canada? En fait, le lecteur français cherche davantage l'exotisme, la couleur locale et la confirmation des stéréotypes que la réalité quotidienne des francophones d'Amérique.

La thèse principale de Sylvain Simard, cependant, est ailleurs. Dans ces ouvrages publiés entre 1850 et 1914, il constate la redécouverte du Canada par les Français, redécouverte accompagnée de (ou causée par?) l'intérêt des milieux politiques et économiques français, mais en tout cas fortement liée à la situation politique de la France et en particulier aux luttes religieuses qui traversent la fin du dix-neuvième siècle. Aussi le Canada exerce-t-il avant tout son attrait sur les milieux traditionnels, le plus souvent monarchistes et catholiques conservateurs (p. 313). Une image conservatrice, très Ancien Régime, imprègne donc les écrits «sérieux» (études, essais, récits de voyage) et elle s'opposera à l'image aventureuse très "coureur des bois», calquée sur l'Amérique de Fenimore Cooper, des romans populaires, quoique cette double image trouvera une sorte de synthèse dans le Maria Chapdelaine de Louis Hémon, par lequel Sylvain Simard termine sa lecture. En ce sens, c'est d'abord un exemple ou un contre-exemple, une vision de leur avenir, une réponse à leur questionnement présent, que les Français recherchent dans ce Canada imaginaire auquel ils se sentent par ailleurs liés culturellement et historiquement. Il est donc normal que cet épisode de renouveau dans les relations entre la France et le Québec s'achève au moment où triomphe la modernité radicale et laïque, juste avant la Première Guerre mondiale et qu'alors s'établisse une plus grande distance entre les deux pays. Ainsi se trouve justifié le paradoxe apparent du titre de cette étude: le Canada imaginaire des Français n'est que le mythe et le reflet de la société française de la fin du dixneuvième siècle.

1 Sylvain Simard, Mythe et reflet de la France. L'image du Canada en France 1850-1914, Ottawa, les Presses de l'Université d'Ottawa, «Cahiers du CRCCF», no 5, 1987, 440 p.

2 Jean Ménard, Xavier Marmier et le Canada, Québec, les Presses de l'université Laval, 1967, et Armand Yon, les Canadiens trançais jugés par les Français de France, (18301839), Québec, les Presses de l'université Laval, 1975. 